City University of New York (CUNY) CUNY Academic Works

2012

\title{
A Librarian's Defense of the Practicable over the Perfect in Scholarly Communication
}

Jill Cirasella

CUNY Graduate Center

\section{How does access to this work benefit you? Let us know!}

More information about this work at: https://academicworks.cuny.edu/gc_pubs/1

Discover additional works at: https://academicworks.cuny.edu

This work is made publicly available by the City University of New York (CUNY).

Contact: AcademicWorks@cuny.edu 
A Librarian's Defense of the Practicable over the Perfect in Scholarly Communication Jill Cirasella

As an academic science librarian who encounters daily the problems and perversities of the traditional system of journal publishing, I welcome Brian A. Nosek and Yoav Bar-Anan's article "Scientific Utopia: I. Opening Scientific Communication." Nosek and Bar-Anan are well informed about the shortcomings of traditional journal publishing and personally experienced with its inefficiencies, and they write with seriousness and imagination about possible improvements to the outdated system. And although I would ordinarily encourage authors to choose open access publishers, in this case I might actually, counterintuitively, applaud the authors for sharing their vision in a journal issued by a traditional and highly profitable commercial publisher. By doing so, they not only address their psychology colleagues but also speak scholarly-communication truth to scholarly-communication power. (It is worth mentioning that the authors also make the article available to all at http://arxiv.org/abs/1205.1055.)

If "perversities" seems like too strong a word in the paragraph in the preceding paragraph, consider this: Universities and grant-funding agencies, many of which are funded by taxpayers, pay researchers to perform research and record their findings in articles. The researchers then give these articles—and often their full copyrights—-to journal publishers for free, and other researchers peer review the articles for free. Libraries then pay dearly for access to these articles, including articles produced by researchers at their institutions. Yes, that's right: Publishers get articles, copyrights, and labor for free, and then rake in huge profits by charging libraries and individuals enormous fees for access to those articles. Journal publishing is of course not cost-free, but too many publishers charge fees that are not justified by the costs of 
journal production and hosting. These publishers may make noble-sounding claims about their commitment to the broad dissemination of information, but make no mistake: They are fettering, not facilitating, scholarly communication and the spread of knowledge. (For a sobering snapshot of commercial publishers' profits, see "The Obscene Profits of Commercial Scholarly Publishers" (Taylor, 2012).)

Academic librarians, who think constantly and carefully about scholarly communication, have been outraged about journal prices and copyright policies for years. However, we often struggle to communicate these problems beyond the library world, in part because many nonlibrarians consider journal subscriptions a library issue that does not affect them, especially when tenure and promotion are pressing concerns. Therefore, librarians prize nonlibrarians such as Nosek and Bar-Anan who immerse themselves in the issues surrounding scholarly communication and inform their peers about what they learn, observe, and imagine. I encourage researchers in every field to step back occasionally from their regular research agendas and discuss with their colleagues, in person and in writing, the state and future of scholarly communication in their disciplines. Articles about scholarly communication do appear in discipline-specific journals, but there need to be more. Indeed, there need to be ongoing conversations in each field and among the fields.

While I have unqualified enthusiasm about the existence and spirit of Nosek and BarAnan's article, I have some reservations about its specifics. For better or worse, I, like many librarians, have a bias toward the practical and practicable, and I favor focusing first on the most pressing and most feasible aspects of scholarly communication reform. In other words, I care about strategy as much as I care about identifying the very best model, and I believe it is more 
strategic to work toward a readily attainable, noncontroversial near-utopia than to focus too narrowly on a specific utopian vision.

I am not suggesting that Nosek and Bar-Anan's proposal is too narrow-not at all. In fact, I am impressed by how far-reaching it is. But their proposal imagines just one possible future, and to strive exclusively toward exactly that future would be to focus too narrowly. The world of scholarly communication needs many proposals for many possible futures, and those proposals need to be scrutinized, compared, attempted, revised, and so on. Furthermore, it is almost certainly not the case that one model will work for all fields. (Somewhat analogously, there are multiple Creative Commons licenses, some of which I prefer to others, but I celebrate all of them as improvements on traditional copyright for scholarly communication. Just as I would never say that all content creators should select the same license, I would never say that all disciplines should employ the same model for scholarly communication.)

So, again, I welcome their proposal, but I do not embrace it to the exclusion of other ideas. More specifically, of their six proposed changes to scholarly communication, I consider the first two necessary, and I look forward to seeing the other four compete with other ideas and evolve and strengthen as a result.

The first proposed change, full embrace of digital communication, is happening already. Some journals are moving more quickly than others away from page limits, discrete issues, and other outdated constraints, but I have every faith that all journals will eventually free themselves from unnecessary vestiges of print publishing. The second proposed change, open access to all published research, is an imaginable but by no means inevitable future, and this change is where researchers, librarians, and others need to focus their reforming energies. Open access to scholarly literature is of utmost importance to the creation and dissemination of knowledge, and 
we all need to work to make it inevitable and universal. Moreover, we cannot jeopardize the open access endeavor by hitching it to less pressing, more controversial projects that might affect the reputation and thus the future of open access.

Unlike the first two proposed changes, which are essentially noncontroversial among people who think seriously about scholarly communication (except, of course, some publishers), the remaining four proposals will be controversial among thoughtful, reasonable people. These four changes_-disentangling publication from evaluation; creating a grading evaluation system and a diversified dissemination system; publishing peer review; and establishing open, continuous peer review_-would significantly alter the flow of publishing and the meaning of a journal. I can imagine a happy future including these changes, but I can also imagine a dysfunctional future.

I am especially skeptical of the idea of assigning grades to research articles- the proposed process seems no less problematic than the current system of peer review. Grades are reductive and not especially meaningful; they are difficult to assign correctly, difficult to interpret, and just as susceptible to politics as written evaluations. Also, any quantitative grading system would be less agile than written opinions, which can focus on whatever parts of a manuscript demand attention. Furthermore, who would pay for these grading services? Would institutions that happily pay publication fees for open access articles also happily pay grading fees for all manuscripts, regardless of quality?

My concerns and questions are not condemnations. They are simply part of the process of identifying and improving good models for scholarly communication. As a librarian, I implore scientists and other scholars to keep thinking, writing, debating, and experimenting. The world of 
scholarly communication is in flux, and researchers have control over its future. And librarians will help every step of the way.

\section{References}

Taylor, Mike. (2012, January 13). The obscene profits of commercial scholarly publishers [Web log post]. Retrieved from http://svpow.com/2012/01/13/the-obscene-profits-ofcommercial-scholarly-publishers/ 